\title{
O DESCASO PATRIMONIAL NO OESTE PAULISTA: ESTUDOS DE CASOS EM REGENTE FEIJÓ-SP
}

Ariane Pedrosa, Fabrícia D. da Cunha de Moraes Fernandes Borges

Universidade do Oeste Paulista - UNOESTE, curso de Arquitetura e Urbanismo, Presidente Prudente, SP. E-mail: ariane pedrosa@hotmail.com

\section{RESUMO}

O presente trabalho, tem o objetivo de contribuir para a reflexão sobre o conceito de Patrimônio Histórico Cultural de maneira que fique evidente seu poder simbólico para a construção da identidade e memória da sociedade. Além de abordar o descaso patrimonial por parte do poder público nas cidades pequenas do interior do Estado de São Paulo, como no caso de Regente Feijó, tendo como objeto de estudo edifícios que demarcaram o surgimento e desenvolvimento da cidade, dando foco à Antiga Rodoviária e a Residência dos moradores ferroviários. Ambos edifícios, formam um conjunto urbano de interesse histórico extremamente relevantes para o Patrimônio Ferroviário, considerando o fato da cidade ter surgido entorno da linha férrea Alta Sorocabana.

Palavras Chave: Patrimônio Histórico cultural, Identidade, Memória, Descaso Patrimonial, Regente Feijó.

\section{THE PATRIMONIAL NEGLECT IN THE WEST OF SÃO PAULO: CASE STUDIES IN REGENTE FEIJÓ- SP}

\begin{abstract}
The present work has the objective of contributing to the reflection on the concept of Cultural Historical Patrimony in such a way that its symbolic power for the construction of the identity and memory of society is evident. In addition to addressing patrimonial neglect by public authorities in the small cities of the interior of the State of São Paulo, as in the case of Regente Feijó, having as object of study buildings that demarcated the emergence and development of the city, giving focus to the Old Road and The residence of the railway residents. Both buildings form an urban complex of historical interest extremely relevant to the Railway Heritage, considering the fact that the city has arisen around the Alta Sorocabana railway line.
\end{abstract}

Keywords: Cultural Historical Property, Identity, Memory, Equity Negligence, Regente Feijó.

\section{INTRODUÇÃO}

A noção de patrimônio, proveniente do termo latino "patrimonium", era associado a conceitos de herança, fossem eles bens de família ou propriedade, recebido de seus antepassados e que deveriam ser transmitidos aos seus descendentes (CAFÉ, 2007).

Durante a Idade Média, com a propagação do Cristianismo, o patrimônio adquire uma importância religiosa, devido à valorização das relíquias, onde os objetos sacros passam a ser partilhados pelos fiéis, como forma representativa da fé e tradição cristã (CAFÉ, 2007).

No mesmo período o patrimônio também passa a ser de interesse para os senhores feudais, de acordo com Fonseca (1997), projetavam em seus castelos e em outras representações linhagens simbólicas de sua existência, portanto esses objetos também são concebidos como patrimônio digno de preservação. 
No Renascimento essa perspectiva é alterada, a valorização da arte dá início a práticas de coleta e catalogação, transformando-os em imensas coleções particulares e antiquários. Para os intelectuais esses objetos eram importantes resquícios da civilização humana (CAFÉ, 2007).

A atuação dos antiquários só entra em declínio, durante a Revolução Francesa, século XVIII, com as transformações políticas e sociais, o Estado passa a intervir nas questões preservacionistas. A partir desse momento inicia-se a proteção legal dos bens culturais, ampliando o conceito como bem herdado por toda geração e não somente vinculados a interesses de grupos sociais isolados como antes. Portanto os bens estariam, a disposição e em benefício do povo.

A noção de patrimônio é, portanto, datada, produzida, assim como a ideia de nação, no final do século XVIII, durante a Revolução Francesa, e foi precedida, na civilização ocidental, pela autonomização das noções de arte e de história. O histórico e o artístico assumem, nesse caso, uma dimensão instrumental, e passam a ser utilizados na construção de uma representação de nação (FONSECA, 1997, p.37).

Os bens do clero e da nobreza passam a ser confiscados, para serem regulamentados pelo Comitê de Instrução Pública. Os objetos em sua maioria foram transferidos para museus, como forma de instruir a população e os edifícios passam a ter uma nova utilização.

A herança dos nobres era apropriada como herança do povo de cada Estado-nação, sendo relidas com novos sinais diacríticos. Uma nova história heroica das nações passou a ser construída, onde não mais os indivíduos reis, líderes, heróis, eram os sujeitos. A partir de então, o novo sujeito da história era o povo (ABREU, 2003, p.31).

O desenvolvimento do conceito de patrimônio, levou a criação de sistemas destinados a proteção e conservação, onde eram compostos, conforme Abreu (2003), de objetos artísticos e edificações ligadas a concepção de monumento histórico. Esses bens representavam a riqueza da nação, seu gênio e história. A França foi grande percussora desse momento, quando em 1830 funda a Inspetoria de Monumentos Históricos, com intuito de inventariar e registrar tais obras (FEITOZA, 2017).

No século XX após a Segunda Guerra, o conceito é ampliado e passa a incorporar bens físicos e não físicos, dividindo-se em duas categoriais: Os bens tangíveis (Material, tudo aquilo que pode ser tocado- ligados a monumentos arquitetônicos, objetos, vestuário, conjuntos naturais) e os bens intangíveis (Imaterial, ligado ao saber fazer humano- ritos, danças, literaturas, comportamentos, receitas) (CAFÉ, 2007).

Com o entendimento atual, patrimônio é um legado que um dado grupo pretende deixar para as gerações futuras. Portanto, todo e qualquer objeto produzido pela humanidade, quando perdem sua funcionalidade podem ser ou não transmitidos posteriormente, isso dependerá do sentimento de posse e valor sentimental atribuídos a esse objeto. E quando esse valor afetivo é adquirido numa determinada época de acordo com um contexto social, seja ele individual ou coletivamente, pode-se dizer que estamos perante a algo sentimental, histórico, social, portanto cultural. Desse modo, segundo Prats (1997), o patrimônio pode ser entendido como uma construção social.

Nas últimas décadas, a preservação do patrimônio histórico cultural ganhou espaço e veio se destacando como assunto relevante a ser discutido nas cidades. Nesse momento de redescobrimento da sua importância, o tema cativou olhares mais cautelosos acerca do assunto, principalmente para os centros históricos das cidades do Oeste Paulista. Adota-se como centro antigo o espaço urbano que no passado se constitui como o primeiro centro da cidade, lugar de 
fundação onde ainda estão edificações consideradas importantes, as quais alocaram parcela da população e comércio (SILVA; FALCÃO; BARBOSA, 2011).

Transformações em torno do patrimônio proporcionam e reforçam uma reestruturação espacial, além de trazer novas exigências. Tal situação impõe uma maior atuação do poder público na regulamentação dos usos e da ocupação do solo, para que o desenvolvimento prometido resulte em real preservação desse bem (SILVA; FALCÃO; BARBOSA, 2011).

A cidade de Regente Feijó, localizada a 555 quilômetros da Capital São Paulo, contém uma concentração de bens históricos significativos, mas com pouca valorização por parte do poder público e da própria comunidade. A população ainda não foi conscientizada da importância do patrimônio cultural, que veio sofrendo graves consequências, exemplo disso é o colapso das edificações antigas e seus processos de abandono e demolição. A expansão urbana desordenada e a busca por uma cidade mais moderna, acelerou esse processo de descaracterização, influenciando negativamente o processo de construção identitária e da memória coletiva.

$\mathrm{O}$ trabalho acadêmico tem por objetivo abordar o conceito de patrimônio histórico cultural e justifica-se pela importância de incitar novos debates e discussões sobre a preservação dos bens de valor cultural e histórico, visto que, além de ser uma fonte de conhecimento do passado, serve também para testemunhar a cultura humana no futuro.

\section{METODOLOGIA}

Para dar suporte a pesquisa, seriam realizados levantamentos qualitativos, através do aprofundamento da linha teórica e elaboração dos conceitos de patrimônio histórico cultural, identidade e memória coletiva, consultas bibliográficas, investigação por meio de levantamentos de documentos, fotografias, estudos de tipologia arquitetônica, levantamento métrico e topográfico do terreno em estudo, análise de antecedentes e por fim as diretrizes projetuais.

\section{O DESCASO PATRIMONIAL EM REGENTE FEIJÓ- SP}

Uma das principais características das cidades contemporâneas, tem sido suas constantes transformações. Os novos hábitos, a ocupação territorial desordenada e a busca por cidades modernas, demonstram cada vez mais a segmentação de interesses por parte da sociedade e poder público.

Esse processo de descaso patrimonial fadado a desmemoria, tem corrompido com o coração das cidades, o patrimônio histórico-cultural-cultural tem se fragmentado, tornando-se cada vez mais difícil o resguardo da identidade local. Uma cidade sem história, é como uma cidade sem passado. Segundo Lynch (2010), para o bom funcionamento da imagem urbana, a cidade deve estar imbuída de três componentes básicos: Identidade, estrutura e significado. Componentes esses que firmaram-se nas cidades do Oeste Paulista através da chegada da Linha Férrea Alta Sorocabana, demarcando o desenvolvimento econômico, social e político de muitas delas.

Nesse cenário, a cidade de Regente Feijó, fundada em 1919 e impulsionada pelo cultivo do café e do algodão, promoveu a instalação de diversas industrias e ao longo do tempo obteve um crescimento tanto territorial quanto de prestações de serviços.

Durante o progresso, inúmeros edifícios (Figura 1) foram sendo implantados no município, cada um referente a um determinado contexto social, e fruto dos sistemas construtivos da época, foram imprescindíveis para a cidade ter se tornado o que é hoje. A busca incessante pelo desenvolvimento, fez com que o patrimônio material fosse pouco a pouco deixado de lado, dando lugar aos interesses privados do mercado imobiliário (HIRAO, 2012). 
Figura 1- Edifícios históricos presentes no município
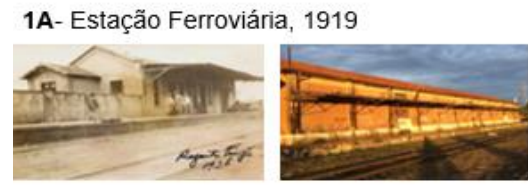

1C- Antigo Casarão, 1936

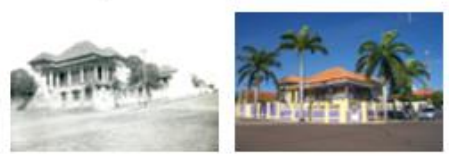

1F-Antiga Rodoviária, 1951
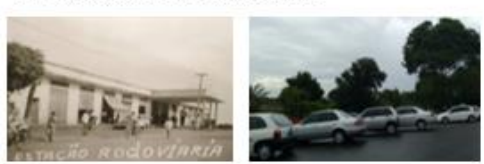

1B- Residência dos Trabalhadores Ferroviários, 1930
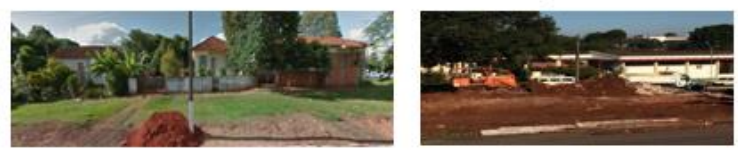

1D- Sociedade Algodoeira do Nordeste Brasileiro, 1940

1E- Posto Dois irmãos, 1940
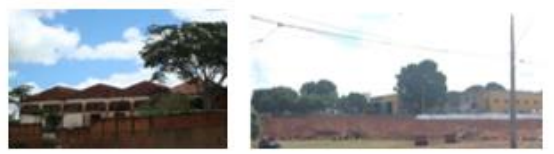

1G- Cine Éden, 1951
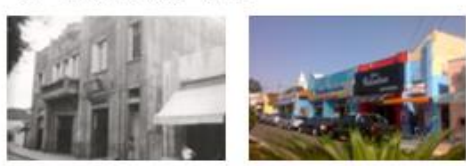

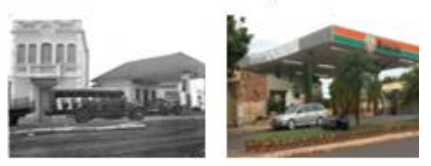

1H- Fórum Municipal, 1958

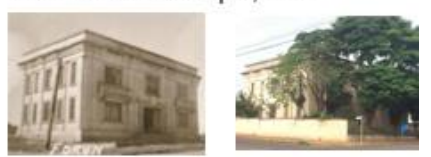

11- Indústria de Laticínio Leco, 1960

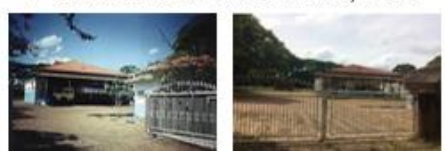

Fonte: Arquivos Históricos de Regente Feijó, editado pela autora, 2017.

Com as afrontas do tempo, a cidade de Regente Feijó, fica a cada dia mais exposta ao esquecimento e perca de seu contexto histórico local, através do descaso patrimonial (Figura 2). Parte disso, deve-se aos interesses públicos e privados, e outra respectivamente pela falta de instrução patrimonial. A conscientização da comunidade, torna-se necessária para a salvaguarda e valorização desses bens no espaço urbano (HIRAO, 2012).

A educação em processo conduz ao conhecimento crítico e esse, por sua vez, a uma apropriação de "pertencimento" por parte das comunidades envolvidas com o seu patrimônio. Assim, a educação patrimonial deve ser entendida também como fator de alfabetização cultural, que pode conduzir os indivíduos a um aprendizado do mundo que os envolve e, desta forma, possibilitar o exercício do direito supremo de interpretar o mundo (BASTOS, 2007, p. 3).

De acordo com a adequação das novas necessidades da sociedade, é de extrema importância que não só preservados, mas estes edifícios sejam inseridos na vida urbana, de modo que se reabilite com caráter e integridade, estando passível não só de admiração mas também de apropriação (HIRÃO, 2012). 
FIGURA 2- Mapeamento de Edifícios Históricos abandonados e demolidos na cidade de Regente Feijó

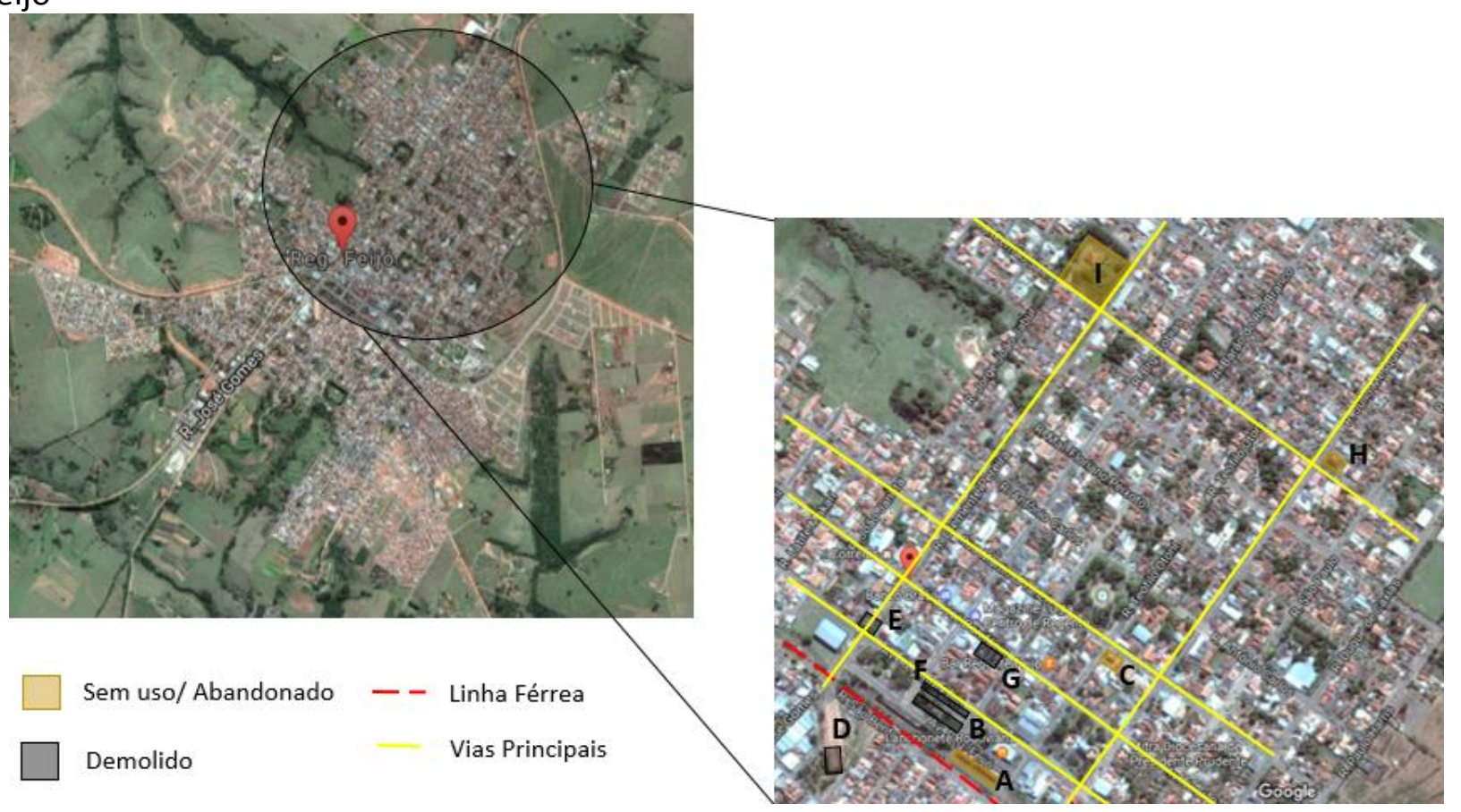

Fonte: Google Earth, editado pela autora, 2017.

\section{CONCLUSÃO}

Após discutir os referenciais teóricos, é possível compreender a importância do patrimônio histórico cultural como norteador da identidade e memória coletiva. E evidencia-se o colapso histórico que os centros das cidades vem sofrendo.

As residências dos moradores ferroviários, bem como os diversos edifícios abandonados/demolidos são um testemunho histórico do surgimento e desenvolvimento da cidade de Regente Feijó, símbolos dignos de preservação.

\section{REFERÊNCIAS BIBLIOGRÁFICAS}

ABREU, Regina. A emergência do patrimônio genético e a nova configuração do campo do patrimônio. In: ABREU, Regina; CHAGAS, Mário (orgs.). Memória e patrimônio: ensaios contemporâneos. Rio de Janeiro: DP\&A, 2003. p. 31.

BASTOS, R, L. O Papel da arqueologia na Inclusão Social, In: Revista do Patrimônio Histórico e Artístico Nacional, 2007, p. 288-301.

CAFÉ, Daniel Calado. Patrimônio, Identidade e Memória: Proposta para a criação do museu do território de. Lisboa, 2007. Disponível em <http://www.museologiaportugal.net/files/upload/mestrados/daniel_cafe.pdf > Acesso em 03/03/2017.

FEITOZA, Paulo Fernando de Britto. Patrimônio Cultural da nação: Tangível e intangível. 2017. Disponível em

http://www.revistas.uea.edu.br/old/abore/artigos/artigos_2/Artigos_Professores/Paulo\%20Feitoz a.pdf> acesso em: 10/01/2017.

FONSECA. Maria Cecília Londres. O patrimônio em processo: trajetória da política federal de preservação no Brasil. Rio de Janeiro: UFRJ/IPHAN, 1997, p. 37. 
HIRAO, Hélio. O Patrimônio arquitetônico e urbanístico de Presidente Prudente: 0 possível preservado. $16 \mathrm{f}$. Presidente Prudente, 2012. Disponível em: < http://revista.fct.unesp.br/index.php/topos/article/view/2514/2247 > Acesso em: 21/04/2017.

LYNCH, Kevin. A imagem da cidade. $2^{\circ}$ Ed. 2010.

SILVA, Georgia Patrícia; FALCÃO, Márcia Teixeira; BARBOSA, Maria Aparecida Ferreira. 0 caso e o descaso do patrimônio cultural da cidade de Boa Vista- RR. 15 f. Roraima, 2011. Disponível em: < http://www.uesc.br/revistas/culturaeturismo/ano5-edicao2/artigo_4.pdf > Acesso em:

03/08/2017. 